19. Дацышен В.Г. Китайская православная церковь накануне и во время Второй мировой войны // Государство, общество, церковь в истории России $\mathrm{XX}$ века: матер. XV междунар. науч. конф. Иваново, 23-24 марта 2016 г. В 2 ч. Ч. 1. Иваново: Изд-во «Ивановский государственный университет», 2016. C. $124-130$.

20. Дионисий (Поздняев), священник. Церковь в Китае: на пути к автономии // Альфа и Омега. 1997. № 3 (14).

21. Ду Иоанн. Распространение Русской Православной Церкви в Тяньцзине и его окрестностях // Китайский Благовестник. 1999. № 2.

22. Печерица В.Ф., Сиренко И.Г. Русская православная эмиграция в Китае в 20 -е - 40-е гг. XX в. // Религиоведение. 2007. № 2. С. 43-48.

23. Поздняев Дионисий, священник. Русская Православная Церковь на Дальнем Востоке в 30-40-е гг. $\mathrm{XX}$ века [Электронный ресурс] // Самый Восточный. Информационно-просветительский портал Хабаровской епархии. - http://pravostok.ru/blog/rysskaya- pravoslavnaya-cerkov-na-dalnem-vostoke-v-30-40-e-godixx-veka.

24. Православие в Китае / под ред. М.Л. Титаренко. М.: Отдел внешних церковных связей Московского Патриархата, 2010. 251 с.

25. Православие в Китае: сбор. матер. выставки / сост. В.В. Селивановский. Благовещенск: Изд-во «Амурская ярмарка», 2013. 68 с.

26. Русак В.С. Православие в Китае в XX веке [Электронный pecypc] // takua.ru. - http://takya.ru/ nuda/pravoslavie-v-kitae-v-hh-veke/main.html.

27. Федорова Ю.С. Русская православная церковь в Северо-восточном Китае. 20-30 гг. ХХ в. // Россия и АТР. 2004. № 3. С. 102-113.

28. Хмыров Д.В. Русская церковная эмиграция в Китае в историко-политическом контексте: от эры милитаристов до японо-китайской войны (19171937) // Христианские чтения. 2013. № 1. С. 155-166.

29. ГАРФ (Государственный архив Российской Федерации). Ф. 9145. Оп. 1. Д. 234.

\title{
MATERIALS OF WHITE EMIGRANT CHURCH ORGANIZATIONS IN CHINA AS A SOURCE ON THE ORTHODOX CHURCH HISTORY
}

(C) 2018

Drobotushenko Evgeny Viktorovich, candidate of historical sciences, dean of History Faculty

Lantsova Yuliya Nikolaevna, candidate of historical sciences, associate professor of History Department Transbaikal State University (Chita, Russian Federation)

Abstract. The paper deals with various aspects of the Orthodox Church history in China on the basis of a rich source - materials of white emigrant Church organizations collected in one large file of the Fund 9145 «Collections of individual documents of various emigrant organizations» of the state archive of the Russian Federation. This file contains correspondence on specific issues as well as various flyers, brochures, newspaper articles, posters, announcements, reports, statements, notes with the characteristics of various aspects of Orthodox history and covers the time period from 1924 to 1936. Articles from the Newspapers «Zarya», «Gong Bao» as well as a spiritual magazine «Bread heavenly», etc. deal with the key issues of the transition of the Chinese clergy under the control of the Synod of bishops of the Russian Orthodox Church outside of Russia under the canonical jurisdiction of the Moscow Patriarchate, etc. Unfortunately, despite the considerable interest in the history of Russian emigration in the second quarter of the $20^{\text {th }}$ century in China, as well as in the history of Orthodoxy in the country, the documents of this file have not been widely known, although they are the supplement of the little-known pages of Orthodox history.

Keywords: Orthodoxy; Church; clergymen; Archbishop; Bishop; Bishops; White emigrant Church organizations; emigrants; Harbin; Shanghai; Russian Spiritual Mission in China; State archive of Russian Federation; archival documents; fund; inventory; business.

УДК 94

DOI 10.24411/2309-4370-2018-14218

Статья поступила в редакцию 14.08.2018

\section{МАТЕРИАЛЬНО-ТЕХНИЧЕСКАЯ БАЗА ФИНАНСОВЫХ ОРГАНОВ ЧЕЛЯБИНСКОЙ ОБЛАСТИ В ГОДЫ ВЕЛИКОЙ ОТЕЧЕСТВЕННОЙ ВОЙНЫ}

(C) 2018

\author{
Ивлев Никита Николаевич, кандидат исторических наук, \\ доцент кафедры социально-гуманитарных дисциплин \\ Южн-Уральский государственный институт искусств им. П.И. Чайковского \\ (2. Челябинск, Российская Федерация)
}

Аннотация. В статье рассмотрено материально-техническое положение финансовых органов на территории Челябинской области, сложившееся в 1941-1945 гг. Приведена структура областных финансовых учреждений, в которую входили финансовые отделы (областной финансовый отдел, городские, районные финансовые отделы), сберегательные кассы и банки долгосрочного кредитования. Изучена динамика изменений материально-технического обеспечения областной финансовой системы в годы войны. Анализ архивных источников наглядно свидетельствует о том, что в первые годы войны материально-техническое обеспечение областной системы финансовых органов находилось в критическом состоянии: не хватало служебных помещений, транспорта, счетных и пишущих машинок и другого необходимого для работы оборудования. Но с началом коренного перелома на фронтах ситуация постепенно начала улучшаться. Увеличивается денежное 

и продовольственное обеспечение, стабилизируется положение с жилыми и служебными помещениями, с транспортом, появляется новое оборудование. Несмотря на трудное положение, материально-техническое обеспечение не оказало значительного влияния на эффективность работы областных финансовых органов. Была сохранена финансовая стабильность как на общесоюзном, так и на региональном уровне. Выполнены и перевыполнены государственные задания по размещению военных займов. Всего в Челябинской области было собрано 1,6 млрд руб., что составляет $2 \%$ от общесоюзных средств, полученных от распространения государственного кредита. Также важнейшим показателем эффективности работы было качественное исполнение областных бюджетов.

Ключевые слова: Великая Отечественная война; Челябинская область; финансовые органы; сберегательные кассы; Промбанк; Торгбанк; Комбанк; материально-техническая база; банки долгосрочного кредитования; мобилизация средств; материально-техническое обеспечение; финансовые отделы; государственный военный заём; бюджеты.

Великая Отечественная война - величайший кризис в истории России ХХ в. Военный и трудовой подвиг солдат и тружеников тыла изучается историкам, описывается писателями и художниками, но еще многие события остаются неизученными. Историография деятельности финансовых органов Советского государства в годы Великой Отечественной войны немногочисленна, и эта тема слабо исследована на всех уровнях, как на союзном и республиканском, так и на региональном. На общесоюзном уровне было опубликовано исследование М.Л. Тамарченко. В работе рассмотрены основные аспекты советской финансовой политики, но не затронуты структура и деятельность финансовых органов [1]. Современная российская историография пополнилась исследованием Е.В. Хохлова о военной экономике СССР накануне и в годы Второй мировой войны, но финансовой системе СССР уделено крайне мало внимания, интересующая нас тема не рассматривается [2]. Некоторые аспекты финансовой политики и практики в годы войны обнаруживаются в уральской историографии. Г.Е. Корнилов проследил изменения в налогообложении сельского населения Урала и сделал вывод о значительном росте налоговых платежей в период войны [3], вопросы финансирования уральских колхозов через счета Сельхозбанка поднял В.П. Мотревич [4], тема налоговых и займовых сборов с населения Урала освещена в отдельном параграфе монографии Н.П. Палецких [5].

Краткий историографический анализ показывает, что тема материально-технического обеспечения финансовых органов не являлась объектом изучения. Наиболее изученной частью функционирования финансовых органов является мобилизация средств населения на покрытие военных расходов. Как правило, тема мобилизации включена в контекст всенародной помощи фронту либо присутствует в исследованиях по социальной политике. Таким образом, системной работы по изучению финансовой политики и практики военных лет не проводилось. Попытка специального комплексного исследования работы финансовой системы и финансовых институтов в годы Великой Отечественной войны была предпринята автором в 2011 г., когда было защищено диссертационное исследование, но большая часть работы еще не была опубликована.

Цель настоящей статьи - раскрыть состояние материально-технической базы финансовых органов Челябинской области в годы Великой Отечественной войны, проанализировать влияние уровня материально-технической обеспеченности на эффективность работы финансовых органов.
Формирование системы финансовых органов Челябинской области происходило в границах общегосударственной концепции с сохранением региональной специфики. Реализуя единые функции и исполняя общие задачи, финансовая система Челябинской области имела свои характерные черты, которые определялись экономикой Южного Урала.

Созданная в тридцатые годы XX в. областная финансовая система состояла из нескольких уровней. Первый уровень составляли финансовые отделы: областной финансовый отдел (облфо) в составе облисполкома, городские и районные финансовые отделы (горфо и райфо) в составах исполкомов соответствующих уровней. Второй уровень представлен управлениями трудовых сберегательных касс, входивших в финансовые отделы, но находившихся под особым контролем исполкомов. Третий уровень состоял из банков долгосрочного кредитования. Все вышеуказанные финансовые органы находились в структуре Народного комиссариата финансов.

Финансовые отделы специализировались на мобилизации денежных средств населения и предприятий. Они аккумулировали и распределяли финансовые потоки в области, контролировали расходование средств на производство, строительство, торговлю и социально-культурную сферы. В их функционал входили: составление и исполнение областного бюджета, бюджетное регулирование, взаимодействие с республиканским, городскими и районными бюджетами. Еще одной функцией было регулирование и оптимизация административно-управленческого аппарата области.

Структура облфо представлена системой следующих отделов: бюджетного, штатного, административно-хозяйственного, налогового, финансирования народного хозяйства, кадров. Кроме отделов существовали несколько управлений: управление государственных трудовых сберегательных касс, контрольно-ревизионное управление, управление государственного страхования [6, л. 2]. Областная структура повторялась на местных уровнях в городских и районных финансовых отделах. К началу 1941 г. в областной системе находился 91 финансовый отдел [7, л. 3]. За годы Великой Отечественной войны структура финансовых учреждений Челябинской области претерпела некоторые изменения. Почти все они были связаны с административно-территориальными реформами. Существенная трансформация произошла в 1943 г., когда в самостоятельную была выделена Курганская область. На 1 января 1944 г. в Челябинской области функционировал 61 финансовый отдел [8, л. 2]. 
В структуру областных финансовых органов также входила система трудовых сберегательных касс. Эти учреждения были основным механизмом мобилизации, хранения и перемещения денежных средств. Местом нахождения областного управления сберегательных касс в годы войны было здание № 59 на улице Спартака в Челябинске (ныне проспект Ленина) [9, л. 17]. Структура сберегательных касс, равно как и финансовых отделов, не претерпела серьезных изменений. Существенным толчком для развития системы трудовых сберегательных касс в области стало прибытие эвакуированного населения и административно-территориальные реформы. Так, на начало 1941 г. в области работали 959 сберегательных касс, из них 220 располагались в городах и $739-$ в сельской местности [10, л. 24]. К 1944-1945 гг. количество сберкасс увеличилось. Кассы открывались на крупных заводах и стройках. В 1945 г. в области были созданы 25 новых сберегательных касс, 10 были ликвидированы [11, л. 2].

Система банков долгосрочного кредитования на территории Челябинской области в годы Великой Отечественной войны была представлена областными правлениями и отделениями Промбанка, Торгбанка, Сельхозбанка и Комбанка.

Работа банков на территории области находилась под контролем как областного финансового отдела, так и центрального правления. Самой разветвленной и обширной была сеть Промбанка, что обусловлено промышленным характером экономики Челябинской области. Важнейшее значение работа Промбанка приобрела в первые годы войны. Именно через систему Промбанка проходило финансирование второй волны индустриализации на Урале, связанной с эвакуацией промышленности из западных областей СССР.

Сеть Промбанка на территории Челябинской области состояла из областной конторы и филиалов, которые делились на отделения и пункты уполномоченных. В начале войны штат областной конторы состоял из 66 человек. В её структуре были: управления, сектора, отделы и группы. [12, л. 218]. В октябре 1942 г. Челябинская областная контора Промбанка была реорганизована, из неё выделили областную и городскую конторы [13, л. 598]. Служебные помещения областной контора Промбанка располагались в здании на ул. Спартака, 58 [9, л. 17].

С началом эвакуации предприятий и активным промышленным строительством наблюдается рост количества филиалов системы Промбанка. В момент наивысшего развития процессов восстановления и налаживания производства эвакуированных предприятий областная система Промбанка имела следующий вид: отделения находились в Магнитогорске, Златоусте, Карабаше, Бакале, Копейске, Каменске; управления - в Катав-Ивановске, Чебаркуле, Аше, Кургане, Шадринске; пункты уполномоченных - в Сатке, Миассе, Троицке, Верхнем Уфалее и Полтавке [14, л. 208].

Областные системы Сельхозбанка и Торгбанка обладали куда меньшей сетью и штатом. Штатное расписание Сельхозбанка накануне войны включало в себя контору, четыре отделения и 27 пунктов уполномоченных [15, л. 40].

В областной конторе Торгбанка было три отдела: контрольно-плановый, бухгалтерия и общая часть. В контрольно-плановом отделе работали пять человек, в бухгалтерии - шесть, в общей части - шесть, всего 18 сотрудников [16, л. 14]. Осенью 1941 г. Челябинский обком ВКП(б) отдал распоряжение соединить отделения Госбанка и ряда специальных банков на районном уровне. Основаниями этого решения было сокращение объема работ и необходимость сокращения расходов и удешевления аппарата [17, л. 301].

После краткого описания системы финансовых органов можно приступить к описанию и анализу материально-технической базы финансовых органов Челябинской области.

Состояние материально-технической базы финансовых органов Челябинской области было крайне проблемным как в годы индустриализации, так и в годы войны. Важнейшим направлением было обеспечение финансовых органов служебными, административными и жилыми помещениями. Так, к концу 30-х гг. почти все финансовые отделы имели свои собственные служебные помещения, а некоторые были обеспечены и жилым фондом, но с началом войны ситуация резко изменилась.

Существенные изменения коснулись финансовых учреждений как областного, так и районного уровня. Так, 10 ноября 1941 г. по решению СНК СССР служебные помещения облфо были переданы Наркомату среднего машиностроения, который был эвакуирован в Челябинск, а позже это строение передано тресту «Челябуголь». Сотрудники облфо были переведены в здание облпотребсоюза. Всю войну руководители областной финансовой системы проработали на улице Кирова, д. 112 [9, л. 17], но в марте 1945 г. облфо был вынужден оставить и это здание. Дыры в кровле привели к повреждению перекрытий, что могло привести к обрушению потолка. После осмотра здания специалистами было принято решение о необходимости капитального ремонта [18, л. 41].

По данным административно-хозяйственного отдела облфо, районные и городские финансовые отделы была обеспечены служебными зданиями на $50 \%$. Многие строения были не достроены или не отремонтированы. Еще одной проблемой было местонахождение служебных помещений в существенном удалении от населенных пунктов. Например, здание Кизильского райфо находилось в 30 км от райцентра. Фонд служебного жилья при финансовых отделах в области был довольно скромен. Так, на балансе облфо было девять жилых зданий, а из всех горфо жилые помещения для служебного пользования имел только Челябинский горфо [13, л. 2].

В 1941 г. на балансе областного финотдела находились четыре автомашины, два велосипеда, одна лошадь. Служебной техникой (пишущими и счетными машинками, сейфами) облфо был обеспечен в полном размере. В отличие от областного центра в большинстве районных финотделов ситуация была значительно хуже: не хватало пишущих машинок (на все райфо осталось семь штук), недоставало транспортных средств. С началом войны в структуру Наркомата обороны были переданы две автомашины и более 20 лошадей [13, л. 2].

За 1942-1943 гг. состояние служебного и жилого фонда финансовых отделов области не изменилось. В 1942 г. областной финотдел по-прежнему работал в здании облпотребсоюза. Только 21 районный фи- 
Материально-техническая база финансовых органов Челябинской области... 07.00.00 - исторические науки и археология

нотдел обладал собственными служебными помещениями, сотрудники остальных райфо продолжали трудиться в арендованных помещениях или делили кабинеты с райсоветами [19, л. 24]. Процесс сокращение фонда служебных площадей не приостанавливался. Так, в городе Сатке уплотнили отделы райисполкома, горфо был переведен в здание райсовета, где он разместился вместе с райфо [20, л. 85].

В конце 1943 г. из 30 районных финотделов в собственных строениях располагались только три, остальные продолжали трудиться в зданиях райисполкомов и в домах коммунального хозяйства [21, л. 160].

В распоряжении облфо было девять жилых домов, а все райфо и горфо обладали 16 жилыми зданиями, но они нуждались в капитальном ремонте (текли крыши, не было отопления, водопровода, канализации). Но даже на эти помещения в аварийных домах была очередь из финансовых работников.

Еще одной существенной проблемой фонда помещений была подготовка к отопительному сезону. В 1941-42 гг. облфо неоднократно обращался в местные комитеты ВКП(б) с просьбой помочь организовать снабжение топливом, так как ответственные за снабжение ведомства не могли обеспечить дровами и углем здания облфо. В 1943 г. ситуация существенно не поменялась. У облфо были карточки на топливо, но не было транспорта, чтобы его привезти [22, л. 18].

Схожие ситуации наблюдались и в других финансовых органах области. Правление областной конторы Промбанка регулярно пыталось найти способы привезти выписанный им уголь со складов [18, л. 147]. Для решения этих проблем находили самые разные способы: добивались дополнительного фи- нансирования или перераспределения имеющихся бюджетных средств для оплаты доставки топлива. В ряде случаев денег не давали, и сотрудникам, чтобы оплатить доставку угля и не мерзнуть на рабочем месте, приходилось вносить собственные средства. Часто использовали личные связи, искали друзей и знакомым, у которых был личный транспорт для перевозки грузов. Так, в 1943 г. профсоюз финансовых и банковских работников обязал управляющего областной конторой Сельхозбанка Алексеева предоставить свою личную лошадь для доставки топлива в Госбанк, Промбанк и Сельхозбанк [25, л. 40].

Сложной оставалась ситуация и с транспортным обеспечением, инвентарем. В 1942 г. в районных финансовых отделах числились 45 лошадей и семь легковых автомашин [19, л. 24]. Имевшиеся в наличии пишущие и счетные машинки нуждались в ремонте, но в районах не было ни запасных частей, ни специалистов по обслуживанию. Из-за нехватки печатной техники возникали конфликты между организациями. Так, в мае 1942 г. эвакогоспиталь № 3758 отказался вернуть пишущую машинку Аргаяшскому отделению Сельхозбанка, так как другой нет и заменить нечем [20, л. 21]. Еще одной большой проблемой стала нехватка сейфов и несгораемых шкафов, что создавало угрозу документам и деньгам.

Коренной перелом на фронте, гарантии безопасности, преодоление промышленного кризиса, связанного с эвакуацией производства, позволили направить дополнительные средства на улучшение материально-технической базы финансовых органов страны. Эти процессы отразились и на территории Челябинской области. Данные о материально-технической и жилищной базе областных финансовых отделов представлены в таблице 1 .

Таблица 1 - Материально-техническая и жилищная база финансовых отделов в 1944-1945 гг. [21, л. 6, 85, $199,217]$

\begin{tabular}{|c|c|c|c|c|c|c|c|c|}
\hline \multirow{2}{*}{ Годы } & \multicolumn{2}{|c|}{ Помещения } & \multicolumn{3}{|c|}{ Транспорт } & \multicolumn{3}{c|}{ Оборудование, инвентарь } \\
\cline { 2 - 9 } & Служебные & Жилые & Машины & Велосипеды & Лошади & $\begin{array}{c}\text { Пишущие } \\
\text { машинки }\end{array}$ & Арифмометры & Сейфы \\
\hline 1944 г. & 10 & 24 & 5 & 20 & 59 & 32 & 60 & 21 \\
\hline 1945 г. & 10 & 47 & 4 & 20 & 69 & 34 & 62 & 38 \\
\hline
\end{tabular}

Из представленной таблицы видно, что в 19441945 гг. шел процесс увеличения жилищного фонда, обеспечивающий потребности сотрудников финансовых отделов; до удовлетворительного уровня было доведено количество счетных и пишущих машин. Эти достижения были связаны с преодолением военного кризиса и улучшением снабжения невоенных отраслей экономики.

Снабжение и материально-техническое обеспечение управления трудовых сберегательных касс было немногим лучше. Почти все центральные и районные правления касс обладали собственными служебными помещениями, агентские кассы находились в почтовых отделениях и в райисполкомах. По распоряжению Челябинского горисполкома центральное правление областных сберкасс передало часть своих площадей другой организации. Оставшихся площадей для нормальной работы не хватало. По отзывам сотрудников, в этих помещениях клиентов негде было посадить для заполнения заявления о вкладе [24, л. 39].

Сложное бытовое положение работников финансовой сферы обсуждалось на уровне обкома и обл- исполкома, но найти выход из сложившейся ситуации на тот момент было невозможно. Например, в июне 1942 г. на партийном собрании облфо заведующий А.И. Коршунов докладывал, что партия сейчас не может улучшить бытовое обслуживание и полагаться можно только на собственные силы [22, л. 17].

Важнейшим моментом в обеспечении эффективной работы финансовой системы было организованное снабжение сотрудников финансовых органов продуктовыми и промышленными товарами. Постановление СНК СССР от 7 апреля 1933 г. № 675 приравнивало нормы снабжения квалифицированных финансовых сотрудников к инженерно-техническим работникам. Но с началом Великой Отечественной войны нормы снабжения финансовых специалистов были уменьшены до норм служащих. Возвращение на довоенный уровень снабжения произошло в 1943 г., но нужно подчеркнуть, что повышение норм снабжения коснулось только ведущих финансовых специалистов (главные, старшие бухгалтеры, инспекторы, ревизоры, заведующие) [25, л. 5, 13].

Существенной проблемой оставалась организация питания сотрудников в рабочее время. В здании, 
где находился областной финансовой отдел, был открыт буфет, но он не мог работать из-за отсутствия стабильного снабжения продуктами. Попытка открыть столовую при облфо была заблокирована санитарными службами. Руководители облфо старались договориться с областным торговым отделом и трестом столовых, которые могли обеспечить отдел горячими обедами или первыми блюдами [26, л. 3].

Вопрос с продовольственным обеспечением не был решен и для руководства финансовыми органами области. Так, в январе 1942 г. партийная ячейка облфо ходатайствовала перед областным и городским советом о прикреплении ведущих сотрудников к специализированным магазинам и столовым [26, л. 4].

Нехватка продовольствия коснулась и банков долгосрочного кредитования. В мае 1942 г. отделения Промбанка в Миассе и Шадринске информировали, что облисполком не включил работников банка в списки на снабжение хлебом. Директор областного правления банка просил облисполком разобраться и выдать хлебные карточки [14, л. 208].

Таким образом, государственная система продовольственного снабжения не могла удовлетворить даже минимальный уровень потребления. Выход был найден в массовом развитии подсобных хозяйств и огородов. Организовать масштабное огородничество в городских условиях при максимальной нагрузке на рабочем месте было сложно. С 1942 г. поиск семян стал обязанностью для всех сотрудников, командированных в сельские районы [22, л. 18]. Проблему с нехваткой семян взяли на себя партийные и профсоюзные организации. Весной 1942 г. профсоюз финансовых и банковских работников обязался обеспечить всех сотрудников семенами и саженцами [24, л. 105].

В 1943 г. правительство СССР выделило для финансовых органов СССР 6,5 млн руб. для организации подсобных хозяйств [25, л. 9]. Челябинскому облфо был передан земельный участок для организации подсобного хозяйства. Партийная ячейка Промбанка решила снабдить всех своих сотрудников землей, семенами и ручным инструментом. Эффект от принятых решений был существенным. Уже осенью 1943 г. сотрудники Промбанка собрали со своего подсобного хозяйства 2 тонны капусты, 400 кг помидоров и 100 кг огурцов. Также сотрудники Промбанка организовывались в бригады по заготовке грибов и ягод [23, л. 145-147]. К 1944 г. ситуация с государственным снабжением начала улучшаться. Более 40 работников областных финансовых органов были включены в списки на дополнительное питание [24, л. 149-150].

Совместными усилиями государства, партии, финансовых работников к середине 1944 г. удалось добиться нормализации ситуации с продовольственным снабжением сотрудников областной финансовой системы.

Подводя итоги состояния материально-технической базы финансовых органов Челябинской области, можно сказать, что оно находилось на невысоком уровне. Уровень материально-технической обеспеченности также варьировался внутри областной финансовой системы: банки долгосрочного кредитования и сберегательные кассы функционировали в более «комфортных» условиях в сравнении с районны- ми и городскими финансовыми отделами. Это различие объяснялось существенно большим вниманием к их работе со стороны партии и местных властей.

Уровень материально-технического обеспечения менялся на протяжении всех пяти военных лет. Если в 1941-1942 гг. положение было просто катастрофическим, то в 1944-1945 гг. происходит стабилизация и прогресс в этой работе. Несмотря на колоссальные сложности в материально-техническом обеспечении, система финансовых органов выдержала испытания военного времени, сохранила и повысила уровень своей работы по контролю над финансовыми потоками и мобилизации средств на нужды фронта.

Оценивать эффективность работы финансовых органов СССР в годы Великой Отечественной войны довольно сложно. Основным показателем качественной работы, конечно, было сохранение финансовой стабильности в тяжелейшие военные годы: контроль над инфляцией, бюджетное планирование, выделение средств как на оборонные мероприятия, так и на социальную политику.

Наиболее показательными результатами эффективной работы могут служить итоги размещения государственных военных займов и исполнение бюджетов Челябинской области в годы войны.

Государственные военные займы - это основная форма неналоговой мобилизации средств населения. Государственные кредиты играли важнейшую роль в военной экономике СССР. Всего за годы войны в Челябинской области было собрано 1,6 млрд руб., что составляет $2 \%$ от всех средств, полученных от распространения облигаций государственного займа по всей территории Советского союза. Одной из особенностей военных займов было то, что они пополняли местные бюджеты. В области оставалось $15 \%$ от средств, собранных с рабочих и служащих, и $90 \%$ от подписки по сельскому населению [27, л. 44].

Исполнение государственного плана по реализации военных займов можно увидеть в таблице 2 .

Таблица 2 - Реализация военных займов на территории Челябинской области [28]

\begin{tabular}{|c|c|c|c|}
\hline Год & $\begin{array}{c}\text { План, } \\
\text { млн руб. }\end{array}$ & $\begin{array}{c}\text { Фактическая } \\
\text { подписка, млн руб. }\end{array}$ & $\begin{array}{c}\text { Выполне- } \\
\text { ние, \% }\end{array}$ \\
\hline 1942 & 305 & 366 & 120 \\
\hline 1943 & 291 & 413 & 142 \\
\hline 1944 & 310 & 347 & 112 \\
\hline 1945 & 295 & 316 & 107 \\
\hline
\end{tabular}

Данные таблицы наглядно свидетельствуют, что подписка по государственным военным займам превосходила плановые показатели, получаемые из Москвы.

Еще одним важнейшим показателем эффективности работы финансовых органов было составление и исполнение бюджетов. Если в мирное время финансовая система стремится добиться сбалансированного бюджета, т.е. выравнивания доходных и расходных частей, то бюджеты военного времени в тыловых областях отличались превышением доходов над расходами. Все сэкономленные средства передавались в союзный бюджет в рамках программы дополнительного финансирования фронта и развития военно-промышленного комплекса. В период жесточай- 
Материально-техническая база финансовых органов Челябинской области... 07.00 .00 - исторические науки и археология

шего кризиса (1941-1943 гг.) финансовые органы Челябинской области смогли перевыполнить даже завышенные планы по доходам.

Если сравнить, как исполнялись бюджеты в годы войны, можно отметить, что расходные статьи никогда не исполнялись полностью. Концепция максимальной экономии средств лежала в основе как составления бюджетов, так и в ходе их исполнения. Ярко этот принцип реализован в 1942 и 1943 гг., когда смогли перевыполнить план доходов, минимизировать свои расходы, направив все сэкономленные средства в республиканский, а потом в союзный бюджет, для финансирования обороны. Итоговые данные бюджетной политики Челябинской области в годы войны можно увидеть в таблице 3.

Таблица 3 - Бюджет Челябинской области в годы войны (в \% к плану) $[29$, л. 4]

\begin{tabular}{|c|c|c|c|c|c|}
\hline $\begin{array}{c}\text { Статьи } \\
\text { бюджета }\end{array}$ & 1941 г. & 1942 г. & 1943 г. & 1944 г. & 1945 г. \\
\hline Доходы & 99 & 110 & 102 & 97 & 94 \\
\hline Расходы & 88 & 79 & 92 & 92 & 92 \\
\hline
\end{tabular}

В тяжелейших условиях Великой Отечественной войны финансовые органы области продолжили активную работу по формированию и исполнению областных бюджетов. Наличие действующего бюджета и последовательное его исполнение доказывают то, что в Советском Союзе не допустили финансового кризиса и финансовой нестабильности в годы войны.

\section{Список литературы:}

1. Тамарченко М.Л. Советские финансы в период Великой Отечественной войны. М.: Финансы, 1967. 143 c.

2. Хохлов Е.В. Военная экономика СССР накануне и в годы Второй мировой войны. СПб.: Изд-во С.-Петерб. ун-та, 2005. 282 с.

\section{MATERIAL AND TECHNICAL BASE OF THE CHELYABINSK REGION FINANCIAL BODIES DURING THE GREAT PATRIOTIC WAR}

(C) 2018

Ivlev Nikita Nikolayevich, candidate of historical sciences, associate professor of Social Sciences and Humanities Department South-Ural State Institute of Arts the name of P.I. Tchaikovsky's (Chelyabinsk, Russian Federation)

Abstract. The paper describes the material and technical position of the financial bodies in the Chelyabinsk Region in 1941-1945. The author provides a structure of regional financial institutions, which included the financial departments (Financial Department of the region, city and districts), savings-banks and long-term lending banks. The paper also examines dynamics of changes in the material and technical support of the regional financial system during the war. The analysis of archival sources clearly shows that in the first years of the war the material and technical support of the regional system of financial institutions was in critical condition: there was not enough office space, transport, calculating machines and typewriters as well as other necessary equipment for the work. But with the beginning of a radical change in the lines the situation gradually began to improve. Both cash and food were increased, the situation with transport, office and accommodation space was stabilized, new equipment appeared. Despite the difficult situation, the material and technical support did not have a significant impact on the effectiveness of the regional financial bodies. Financial stability was maintained both at the nationwide and regional levels. The government targets of military loans distribution were not only performed but also beaten. In total, 1,6 billion rubles were collected in the Chelyabinsk Region, which is $2 \%$ of the nationwide funds received from the distribution of the government loan. The most important indicator of the work efficiency was the qualitative performance of regional budgets.

Keywords: Great Patriotic War; Chelyabinsk Region; Financial bodies; savings-banks; Prombank; material and technical base; Torgbank; Combank; material and technical maintenence; Finance departments; government war loan; budgets. 